\title{
ABUSO SEXUAL INFANTIL: ASPECTOS HISTÓRICOS, LEGALES Y DAÑOS AL DESARROLLO INFANTIL
}

\section{ARTÍCULO DE REVISIÓN}

GONÇALVES, Natamy de Almeida ${ }^{1}$, DIAS, Camila Santos²

GONÇALVES, Natamy de Almeida. DIAS, Camila Santos. Abuso sexual infantil: aspectos históricos, legales y daños al desarrollo infantil. Revista Científica Multidisciplinar Núcleo do Conhecimento. Año 06, Ed. 09, Vol. 01, págs. 183-208. Septiembre 2021. ISSN: 2448-0959, Enlace de acceso: https://www.nucleodoconhecimento.com.br/psicologia-es/danos-al-desarrollo

\section{RESUMEN}

Debido a que es una violencia que afecta a varios niños, niñas y adolescentes en el mundo a lo largo de la historia, el abuso sexual infantil requiere una atención cercana, considerando que es un fenómeno complejo y, en muchos casos, difícil de identificar, siendo el abusador generalmente una persona de confianza de la familia y de quien se espera que cuide a la víctima, como padres biológicos, padrastros, tíos o amigos cercanos, por ejemplo. Además, la mayoría de los casos de abuso sexual ocurren en el propio hogar de la víctima, donde poco se espera que el niño y adolescente se encuentra en una situación vulnerable. Con base en los factores descritos, esta investigación presenta la siguiente pregunta guía: ¿qué es el abuso sexual y cuáles son sus impactos en el desarrollo infantil? Este artículo tuvo como objetivo revisar los aspectos históricos y legales del abuso sexual, explorando las complejidades de sus definiciones y presentando los posibles efectos en la víctima.

\footnotetext{
${ }^{1}$ Postgrado en Neuropsicología de la Facultad de Tecnología, Ciencias y Educación - FATECE, postgrado en Psicología Organizacional y del Trabajo en la Fundación Hermínio Ometto y graduado en Psicología de la misma institución.

${ }^{2}$ Consejero. Magíster en Psicología como Ciencia y Profesión (PUCCamp), Especialista en Educación y Psicopedagogía (PUCCamp), Especialista en Neuropsicología (Instituto del Hospital Israelí Albert Einstein), Licenciado en Psicología (Fundación Hermínio Ometto - FHO).
}

RC: 98976

Disponible: https://www.nucleodoconhecimento.com.br/psicologia-es/danos-aldesarrollo 
Para ello, se realizó una revisión bibliográfica de carácter cualitativo, descriptivo y exploratorio, planteando reflexiones sobre el tema. Se vio que el niño y el adolescente no siempre contaron con apoyo legal, habiendo sufrido varias violencias sin el debido castigo a sus agresores. Con el tiempo, se están instituyendo leyes y, en el Brasil, el Estatuto del Niño y el Adolescente (ECA) ha marcado un momento de determinación de los derechos de la infancia y la adolescencia, estableciendo mecanismos de protección, incluso contra la violencia como el abuso sexual. Finalmente, se consideró en este estudio que existe una falta de información a la población sobre el tema, lo que corrobora la reproducción del delito antes mencionado. Se observó que, considerando el daño a la salud biopsicosocial de la víctima y su familia, se realizaron estudios y proyectos de prevención, así como se instituyeron diferentes formas de denuncia de este delito. Se concluyó que existe la necesidad de elaborar estrategias para preparar a las familias, profesionales e instituciones encargadas de garantizar los derechos de los niños, niñas y adolescentes para que puedan contribuir a fortalecer la lucha contra el abuso sexual.

Palabras clave: Abuso Sexual, Agresión Sexual Infantil, Niño y Adolescente.

\section{INTRODUCCIÓN}

Cuando se trata de un tema presente en diferentes partes del mundo y en diversos períodos históricos, el abuso sexual se mantiene hoy en día y es un tema importante a abordar, ya que dicha violencia se ha reproducido continuamente. Waiselfisz (2012) muestra que, según los registros del Sistema de Información de Enfermedades de Notificación Obligatoria (SINAN), en 201110.425 niños que fueron víctimas de abuso sexual fueron tratados en Brasil. En 2018, Brasil registró al menos 32.000 casos de abuso sexual contra niños y adolescentes en 2018, la tasa más alta de notificaciones jamás registrada por el Ministerio de Salud. Desde 2011, los agentes de salud tienen la obligación de computar la atención. Desde entonces, las cifras crecen año tras año, y suman un total de 177.300 notificaciones a nivel nacional[3]. Sin embargo, como lo denotar Aded et al. (2006), se cree que los casos

RC: 98976

Disponible: https://www.nucleodoconhecimento.com.br/psicologia-es/danos-aldesarrollo 
identificados o reportados no dicen sobre la realidad del número de casos. Una de las razones es que, en la mayoría de los casos, el agresor es muy cercano o parte de la familia de la víctima; otro factor es la falta de identificación de los casos, o incluso la creencia de que no hay forma de probar el acto de abuso, entendiendo como evidencia concreta solo el examen médico. Por lo tanto, se cree que el número de casos es mucho mayor de lo estimado.

Con base en los factores descritos, esta investigación presenta la siguiente pregunta guía: ¿qué es el abuso sexual y cuáles son sus impactos en el desarrollo infantil? Este artículo tuvo como objetivo revisar los aspectos históricos y legales del abuso sexual, explorando las complejidades de sus definiciones y presentando los posibles efectos en la víctima.

Se trata de una revisión bibliográfica de carácter cualitativo, descriptivo y exploratorio, para lo cual se utilizaron libros como fuente de datos, además de artículos científicos que se encontraron en el sitio de búsqueda Google. Algunos sitios que presentan datos importantes sobre el tema también se utilizaron en esta investigación.

Teniendo en cuenta que el abuso sexual es una violencia que ocurre de maneras que suelen dificultar su identificación, además de provocar muchas dudas de cómo afrontarlo, es necesario desarrollar más investigación para que cada vez se dé más conocimiento de los mecanismos que involucran a este delito y, así, se establezcan más estrategias de combate. Así, esta investigación muestra su relevancia social y científica, contribuyendo a la clarificación sobre el tema y a que se realicen otras investigaciones a partir del mismo.

\section{ABUSO SEXUAL: DEFINICIONES, HISTORIAS, LEYES}

El abuso sexual es un fenómeno social que necesita una atención refinada porque es un tema complejo, que involucra diferentes problemas y genera sufrimiento para

RC: 98976

Disponible: https://www.nucleodoconhecimento.com.br/psicologia-es/danos-aldesarrollo 
muchos niños, adolescentes y familias, que es uno de los varios tipos de violencia. Considerando las diversas definiciones de abuso sexual, se puede destacar la dada por el Ministerio de Salud (BRASIL, 2002, p.13):

\begin{abstract}
Abuso sexual - consiste em todo ato ou jogo sexual, relação heterossexual ou homossexual cujo agressor está em estágio de desenvolvimento psicossexual mais adiantado que a criança ou o adolescente. Tem por intenção estimulá-la sexualmente ou utilizá-la para obter satisfação sexual. Apresenta-se sobre a forma de práticas eróticas e sexuais impostas à criança ou ao adolescente pela violência física, ameaças ou indução de sua vontade. Esse fenômeno violento pode variar desde atos em que não se produz o contato sexual (voyerismo, exibicionismo, produção de fotos), até diferentes tipos de ações que incluem contato sexual sem ou com penetração. Engloba ainda a situação de exploração sexual visando lucros como é o caso da prostituição e da pornografia.
\end{abstract}

Así, al ser considerado como un acto de violencia, el abuso sexual puede cometerse de varias maneras, desde aquellas en las que no hay contacto físico del agresor con el niño o adolescente, como el voyeurismo en el que se produce la observación de la desnudez de la víctima para obtener satisfacción sexual, y el exhibicionismo, en el que el agresor exhibe sus propios órganos sexuales. También puede ocurrir al mostrar videos y revistas pornográficas a la víctima, despertando su sexualidad de una manera temprana y tergiversada; dar dinero, dulces o regalos para el niño o adolescente para permitir que el agresor abuse de su cuerpo; violarla con sexo oral, que también es un medio de transmisión de enfermedades de transmisión sexual (ETS); o incluso mantener relaciones sexuales vaginales y annaise. Puede ocurrir incluso sin que la víctima se den cuenta, o hasta el punto de causar lesiones físicas y enfermedades psicológicas. Además, dicho abuso no solo es cometido por hombres adultos sobre los niños: puede ser perpetrado por adolescentes, mujeres, ancianos y por diferentes personas en diferentes circunstancias. Esta variación en las formas en que puede ocurrir el abuso sexual puede llevar a una dificultad para identificar algunos tipos de que a menudo no son reconocidos por los adultos como tales (BRASIL, 2002).

RC: 98976

Disponible: https://www.nucleodoconhecimento.com.br/psicologia-es/danos-aldesarrollo 
Además, como lo puntúa el Ministerio de Salud (BRASIL, 2002), el abuso sexual abarca la explotación sexual, que es cuando involucra dinero, regalos, o algo así, en una comercialización del cuerpo del niño y/o adolescente, como en los ejemplos mencionados, que son la prostitución y la pornografía. Sin embargo, como señalan Vega y Paludo (2015, p.48), "definir la explotación sexual ha sido una ardua tarea, incluso para el ámbito académico". Faleiros y Campos (2000), en un análisis del vocabulario del tema, identificaron una inexactitud terminológica. Los autores dan un ejemplo: el abuso sexual se estableció como un delito sexual, la victimización sexual, el abuso sexual, la agresión sexual, la violencia sexual, la explotación sexual, el abuso sexual, la indignación sexual y las lesiones sexuales. Para nombrar la violencia intrafamiliar, se encontraron los siguientes términos: incesto, abuso sexual incestuoso, violencia sexual doméstica, abuso sexual doméstico.

O uso sexual de menores de idade com fins lucrativos é designado ora como prostituição infanto-juvenil, ora como abuso sexual, ora como exploração sexual comercial. Por outro lado, um mesmo termo pode designar distintas realidades, como, por exemplo, o termo exploração sexual é utilizado pela OMS para designar situações de abuso sexual intra e extrafamiliar e prostituição, enquanto muitos autores o utilizam referindo-se apenas à exploração sexual comercial (FALEIROS; CAMPOS, 2000, p.4).

Por lo tanto, también hay divergencias entre los autores con respecto al vocabulario apropiado para cada situación. Sin embargo, para Faleiros y Campos (2000), el uso de términos diferentes como sinónimos y como si fueran equivalentes a un mismo concepto, no es sólo terminología, sino una cuestión de alcance epistemológico, es decir, denuncia la falta de conceptualización del problema. Esta incertidumbre teórica y conceptual se debe a la complejidad y diversidad, así como al hecho de que el deshacer, la conciencia y el afrontamiento de este problema son aún recientes, así como la preocupación por la infancia, como se verá a continuación.

Además de ocurrir de diferentes maneras, el abuso sexual infantil se origina en diferentes lugares del planeta y se describe desde la antigüedad, como lo demuestran Aded et al. (2006). Sin embargo, el progreso en la prevención y

RC: 98976

Disponible: https://www.nucleodoconhecimento.com.br/psicologia-es/danos-aldesarrollo 
suavización de las consecuencias fue poco. Lo que puede dificultar el afrontamiento del problema es el hecho de pasar por complejidades culturales, religiosas, jurídicas y profesionales de todo el mundo.

Oliveira (2006) señala que a lo largo de la historia, una de las características que marcó la cultura humana fue la negligencia contra los niños y adolescentes, ya que no existía la idea de la fragilidad como característica de la infancia, y este tema fue poco discutido, al igual que no existían políticas de protección.

El autor presenta varios puntos de la historia que ejemplifican este abandono, denotando que en muchos pueblos de la antigüedad, el abuso sexual infantil se consideraba normal y, además, muchos de estos pueblos no distinguían entre el niño y el adulto, como en Esparta, por ejemplo. También afirma que en Occidente, durante la Edad Media, esta distinción tampoco se hizo, y el niño permaneció expuesto a diferentes tipos de castigos; "[...] tan pronto como estuvo sin la necesidad de atención materna básica, fue vista como adulta y así creció" (OLIVEIRA, 2006, p. 11). Así, el niño muy pequeño no era considerado como un ser humano y la tasa de mortalidad era alta, hecho que se entendía como un fenómeno común.

Azambuja (2006, p.3) presenta que fue sólo a finales del siglo 17 que el niño comenzó a tener una distinción de la persona adulta. Hasta este momento, las escuelas no estaban organizadas por edad, siendo atendidas por niños y adultos en el mismo lugar. Para el autor, "[...] con la aparición de la comprensión de que la infancia es una fase distinta de la vida adulta, el castigo, el castigo físico, las palizas a través de látigos, palos y hierros se utilizan como instrumentos necesarios para la educación" (AZAMBUJA, 2006, p.3). En 1780, en Inglaterra, los padres podían condenar a los niños a la horca, bajo más de doscientos tipos criminales. En Nueva York, en 1871, una niña sufrió graves malos tratos y, como no había lugar para tal denuncia, el caso de la niña Mary Ellen fue finalmente remitido a la Sociedad para la Prevención de la Crueldad contra los Animales, para que pudiera ser investigado por

RC: 98976

Disponible: https://www.nucleodoconhecimento.com.br/psicologia-es/danos-aldesarrollo 
el tribunal. El caso, que causó mucha indignación de la población, fue lo que incitó a la fundación de una sociedad centrada en la protección del niño.

Según Azambuja (2006), con respecto a Brasil, las primeras embarcaciones lanzadas al mar por Portugal, estaban compuestas por hombres y niños huérfanos por el rey, que prestaban servicios durante el viaje y eran sometidos a abusos sexuales por parte de los marineros. Ella dice que si ocurrían tormentas, los niños eran los primeros "cargamentos" en ser arrojados por la borda.

Guerra et al. (2013) señalan que hasta principios del siglo XX, el Estado no se preocupaba por desarrollar políticas sociales dirigidas a niños, niñas y adolescentes. Así, la Iglesia Católica fue quien desarrolló importantes acciones para cuidar a los niños y adolescentes llamados "abandonados". Las Casas Santas de misericordia no sólo se preocupan por los enfermos y los enfermos, sino también por los niños cuyos derechos han sido violados. Así, en un intento por reducir el número de bebés concebidos fuera del matrimonio y que fueron abandonados incluso en las calles, debido a las presiones sociales de la época, la Iglesia Católica creó la Rueda de los Expuestos. Se trataba de un dispositivo cilíndrico en el que se colocaba y dejaba al niño, con el fin de garantizar el anonimato de quienes cometía el abandono.

Al final de la Primera Guerra Mundial, las organizaciones internacionales recién construidas comenzaron a articular códigos de derechos humanos. Los nuevos órganos han comenzado a prestar atención específicamente a los derechos del niño. La recién creada Agencia Internacional del Trabajo (ahora la Organización) devolvió sus convenios para garantizar los derechos de los niños trabajadores, así como en 1919, en la Convención sobre el Trabajo Nocturno de los Adolescentes (Industria); también en 1921, la Convención sobre la Edad Mínima (Agricultura). Sin embargo, la mayor parte de la legislación producida entre las dos guerras mundiales no explica la especificidad del derecho de los niños y adolescentes a diferencia de los derechos directos de los adultos (UNICEF, 2009).

RC: 98976

Disponible: https://www.nucleodoconhecimento.com.br/psicologia-es/danos-aldesarrollo 
La primera definición de derechos formales del niño, que fue creada por las nacientes organizaciones internacionales, se originó a partir del trabajo de Eglantyne Jebb, quien fundó Save the Childrenen Inglaterra en 1919, y se estableció en Ginebra al año siguiente, la Unión Internacional Save the Children, para recaudar fondos enayuda de emergencia a los niños que sufren como resultado de la Primera Guerra Mundial. Jebb, en 1923, declaró su posición sobre los derechos del niño: "[...] Creo que debemos reclamar ciertos derechos para el niño y trabajar para que sean reconocidos internacionalmente" (UNICEF, 2009, p.4). Así, la Unión Internacional Save the Children creó la propuesta preliminar de una declaración que reclamaba derechos específicos a la población infantil e hizo que la Sociedad de Naciones la adoptara en la Declaración de Ginebra de los Derechos del Niño el 26 de septiembre de 1924.

Así, en la Declaración de Ginebra se examinaron cinco principios básicos: el derecho a condiciones para el desarrollo material y espiritual; el derecho a la prioridad en situaciones de riesgo; derecho a ayudar en circunstancias de hambre, discapacidad, enfermedad, delincuencia o orfandad; el derecho a una formación que guíe al niño a la vida en sociedad; y el derecho a la protección contra la explotación (UNICEF, 2009).

Según el Fondo de las Naciones Unidas para la Infancia (UNICEF, 2009), la Segunda Guerra Mundial corroboró la creación de la Organización de las Naciones Unidas (ONU). La fusión entre la Asociación Internacional para el Bienestar del Niño, establecida en Bruselas y la Unión Internacional Save the Children, dio lugar a la Unión Internacional para el Bienestar del Niño (International Union for Child Welfare - IUCW), que llevó a las Naciones Unidas a respaldar la Declaración de Ginebra.

El sitio web de Portal Brasil[4] muestra que en 1927, el país promulgó el primer Código de Menores. En ese momento, casos de alto perfil y gran repercusión pública llevaron al entonces presidente Washington Luís a determinar que 18 años debería

$\mathrm{RC}: 98976$

Disponible: https://www.nucleodoconhecimento.com.br/psicologia-es/danos-aldesarrollo 
ser la edad mínima para los delincuentes en prisión. Lo que le sucedió al niño Bernardino de 12 años fue uno de esos casos. En 1926, el niño, que era limpiabotas, se enojó con un cliente debido a su negativa a pagar por el servicio prestado en las calles de Río de Janeiro. La niña le habría arrojado pintura a este tipo, por lo que terminó en la cárcel durante cuatro semanas. Bernardino fue violado en la celda por 20 adultos, lo que causó indignación en los médicos cuando el niño fue a santa casa.

Así, la difusión del caso causó una fuerte polémica, iniciando una discusión pública que llegó a las ruedas del Congreso, así como del Palacio de Catete, donde fue lugar del gobierno federal. Así que el mandatario eligió el 12 de octubre (Día del Niño) para firmar el Código del Menor, que fue la primera legislación en el país para la niñez y la adolescencia específicamente. Un artículo de este código prohibió la Rueda de los Expuestos. "Con el código, la madre tendría que registrar al niño y así entregarlo a un orfanato" (BRASIL, s/d).

El sitio web de la Declaración Universal de los Derechos Humanos[5] (DUDH) muestra que el 10 de diciembre de 1948, en París, dicha declaración fue proclamada por la Asamblea General de las naciones, a través de la Resolución 217 A (III). Es un documento que marcó la historia de los derechos humanos. La DUDH fue desarrollada por diferentes representantes de diversos orígenes legales y culturales de todo el mundo, y luego es una norma común para que llegue a todos los pueblos y naciones. Esta declaración viene con la opinión de que el hombre tiene derecho a una vida digna: "Considerando que el reconocimiento de la dignidad inherente a todos los miembros de la familia humana y sus derechos iguales e inalienables es el fundamento de la libertad, la justicia y la paz en el mundo [...]" (DUDH, 1948).

En esta ocasión, la ONU estaba más comprometida con la discusión de los principios de la DUDH, pero la propia IUCW defendió la idea de un nuevo documento, que era específico para los derechos del niño, actualizando la declaración anterior y reiterando el principio de que el niño debe recibir lo que la

RC: 98976

Disponible: https://www.nucleodoconhecimento.com.br/psicologia-es/danos-aldesarrollo 
humanidad tiene para ofrecer mejor. La Declaración de los Derechos del Niño no fue adoptada por la ONU hasta el 20 de noviembre de 1959. El respaldo de la Asamblea General es importante, ya que pone de relieve la necesidad de que los derechos del niño se examinen por separado. La Declaración de los Derechos del Niño destacó el bienestar emocional del niño y garantizó su derecho a ser priorizado al recibir protección de emergencia. "A pesar de estos cambios, el documento de 1959 mantuvo un enfoque de búsqueda de cuidados, con el objetivo de salvar, proteger y proteger al niño, dando poca importancia al aumento de su poder" (UNICEF, 2009, p.5).

Inoue y Ristum (2008) denotan que la violencia ha sido la principal causa de muerte principalmente en audiencias jóvenes y infantiles. En los Estados Unidos, no fue hasta 1960 que la violencia contra los niños fue vista como un problema médicosocial. "[...] especialmente los pediatras comenzaron a tratar el tema que muestra las secuelas del maltrato y las discrepancias entre la evidencia radiológica sobre las lesiones y las explicaciones de los agresores" (MINAYO, 2002, p. 109). Aunque este movimiento dentro de la medicina provocó críticas y acusaciones de "medicalización de la violencia", tuvo una gran influencia en la producción teórica, desencadenando la investigación, así como en los movimientos a favor de la defensa de los derechos de los niños. Así, el campo médico inició una repulsión social sobre el abuso sexual, que tomó consistencia también de Estados Unidos, junto con el fortalecimiento del movimiento feminista de 1970.

El año 1973 estuvo marcado por un acontecimiento que hizo que el 18 de mayo, día importante en el calendario del Ministerio de Sanidad, se memorado hasta nuestros días. El caso es que, en esta fecha, Araceli Cabrera Crespo, de nueve años, desapareció de la escuela donde estudiaba, ya no siendo vista con vida. El sitio web del Consejo Nacional de Salud explica que "Araceli fue golpeada, violada, drogada y asesinada en una orgía de drogas y sexo. Su cuerpo, su rostro estaba principalmente desfigurado con ácido" (BRASIL, s/d). Seis días después del incidente, el cuerpo fue encontrado en un terreno baldío cerca del centro de la

RC: 98976

Disponible: https://www.nucleodoconhecimento.com.br/psicologia-es/danos-aldesarrollo 
ciudad de Vitória, Espírito Santo. Tal martirio tuvo gran trascendencia, por lo que esta fecha es considerada y recordada como el Día Nacional de Lucha contra el Abuso y Explotación Sexual de Niños, Niñas y Adolescentes.

Entre los años 1960 y 1970, la movilización por los derechos de los niños, niñas y adolescentes fue realizada por organizaciones no gubernamentales (ONG), lo que provocó grandes avances; de esta manera, estas organizaciones instaron a las Naciones Unidas a declarar 1979 Año Internacional del Niño, en una propuesta para llamar la atención sobre el problema de la infancia. "Una vez establecido este acuerdo, el Gobierno de Polonia presentó a la Comisión de Derechos Humanos de la ONU un texto preliminar de la Convención sobre los Derechos del Niño" (UNICEF, 2009, p.5). Por lo tanto, se evidenció que la finalización de este documento requeriría una mejor preparación y más tiempo. Así, el proceso se prolongó durante una década, considerando que la redacción de un tratado que involucra varias áreas de interpretación cultural y social es un trabajo que requiere cautela.

Minayo (2002) dice que en la década de 1980, en el campo de la salud pública mundial, la violencia se presenta como un tema sustantivo. Los movimientos de atención especializada y prevención surgen del reconocimiento de la morbilidad y mortalidad a través de la violencia, como un grave problema para la salud en sus aspectos sociales, así como el objetivo de la atención primaria, secundaria y terciaria. También en 1980, en Brasil, se empezaron a pensar propuestas, al ritmo del movimiento social que corroboró la Constitución de 1988. Solo este año el niño es considerado sujeto de derechos, gracias a la Constitución Federal, y tendrá la Convención de las Naciones Unidas, en una nueva era de defensa de los derechos de los niños, niñas y adolescentes.

Tres años antes de esta constitución, el 4 de julio de 1985, el Centro Regional para el Cuidado del Maltrato Infantil (CRAMI) fue fundado por un grupo compuesto por diferentes profesionales pertenecientes a la Pontificia Universidad Católica de Campinas (PUC-Campinas), habiendo involucrado a representantes de diversos

RC: 98976

Disponible: https://www.nucleodoconhecimento.com.br/psicologia-es/danos-aldesarrollo 
sectores de la comunidad, como el Orden de los Abogados de Brasil (OAB) Campinas, Juzgado de Menores, entre otros. Según el propio sitio web de CRAMI[6], "preocupados por los casos rutinarios de niños que llegan a las agencias públicas, presentando marcas de palizas, quemaduras, abrasiones, hemorragias internas, este grupo fundó CRAMI". Muchos de estos niños murieron, y los responsables lo justificaron como una caída o falta de atención del propio niño. Con el tiempo, se construyó un protocolo para atender los casos de violencia doméstica. A partir de la conclusión del caso, se recogieron datos y la trabajadora social facilitó el procedimiento de atención en los domicilios de las víctimas, con el objetivo de tener contacto con la situación real y, dependiendo de la gravedad del caso, remitir a la víctima al Juzgado de la Infancia.

El sitio web de CRAMI también informa que "el trabajo desarrollado por los profesionales altamente calificados de CRAMI comenzó a convertirse en una referencia y alentó la apertura de otros CRAMls en el estado de São Paulo". Por determinación del Sistema Único de Asistencia Social (SUAS), en 2014 CRAMI extendió su atención a todas las personas en situación de vulnerabilidad y riesgo social, de no estando ya restringida a la atención de niños, niñas y adolescentes víctimas de violencia intrafamiliar. Es una entidad no gubernamental, sin fines de lucro, y cuenta con la asistencia de psicólogos, trabajadores sociales y educadores sociales, que sigue la misión, según el sitio web, de "Construir un futuro mejor para los niños, adolescentes y víctimas vulnerables de la violencia doméstica".

El 20 de noviembre de 1989, la Asamblea General de la ONU adoptó la Convención sobre los Derechos del Niño, entrando en vigor el 2 de septiembre de 1990. Este es el más amplio de todos los tratados de derechos humanos e instrumentos jurídicos para la protección de los derechos del niño. Aunque existen disposiciones en defensa de los derechos del niño en el equipo internacional de derechos humanos, la Convención es la primera en abarcar y articular todos los aspectos pertinentes de los derechos importantes para el niño, ya sean económicos, culturales, políticos y

RC: 98976

Disponible: https://www.nucleodoconhecimento.com.br/psicologia-es/danos-aldesarrollo 
sociales. Aún así, fue el primer equipo internacional que reconoció explícitamente que el niño es un actor social que posee sus propios derechos (UNICEF, 2009).

Según UNICEF (2009, pág. 2), "por medio de las disposiciones del tratado, los Estados Partes están obligados por ley a satisfacer los derechos de todos los niños". La Convención prevé 54 artículos y se basa en cuatro principios básicos: el interés superior del niño; la no discriminación; el respeto de las opiniones del niño; y el derecho a la supervivencia y el desarrollo. El objetivo amplio que tiene y la importancia que da a la representación que favorece al niño determinan la pertinencia incesante de todas las acciones encaminadas a satisfacer los derechos del niño. "La Convención reafirma y enriquece los derechos humanos de manera significativa" (UNICEF, 2009, pág. 2). Los reitera aplicando directamente al niño muchos de los principios esenciales de los documentos internacionales de derechos humanos que preexistían, como la no discriminación y la universalidad; los fortalece estableciendo y ampliando dispositivos incluidos en otros equipos de derechos humanos, aclarando las responsabilidades de los Estados Partes en relación con el niño. Integra los derechos del niño que no se incorporaron ampliamente. Hace hincapié en que la responsabilidad de la realización de los derechos del niño debe atribuirse a quienes tienen deberes relacionados con él, como la familia y las personas responsables del niño y los Estados Partes.

La convención tiene un significado que va más allá de sus implicaciones legales. El instrumento también contribuyó a una transformación en las actitudes hacia la infancia. En dever, la Convención determinó los términos de la infancia, estableciendo las normas mínimas para el cuidado, el tratamiento, la supervivencia, la protección, la participación y el desarrollo, que son los derechos de todas las personas cuya edad es menor de 18 años. Sus artículos reafirman que es necesario proteger la infancia como un período diferente de la edad adulta y establecer un tiempo durante el cual el niño crece, aprende, juega y se desarrolla, para que luego los derechos del niño se realicen plenamente (UNICEF, 2009).

RC: 98976

Disponible: https://www.nucleodoconhecimento.com.br/psicologia-es/danos-aldesarrollo 
Como muestra Lemos (2008), inaugurando una nueva perspectiva de derechos y deberes basada en la doctrina de la protección integral, el Estatuto de la Niñez y la Adolescencia (ECA), fue promulgado en 1990, como Ley Federal № 8.069/90, garantizando el respeto del niño y el adolescente como personas en particular el desarrollo:

Art. 3o A criança e o adolescente gozam de todos os direitos fundamentais inerentes à pessoa humana, sem prejuízo da proteção integral de que trata esta Lei, assegurando-se Ihes, por lei ou por outros meios, todas as oportunidades e facilidades, a fim de Ihes facultar o desenvolvimento físico, mental, moral, espiritual e social, em condições de liberdade e de dignidade (BRASIL, 1990).

Esta ley establece un nuevo diagrama, estableciendo diferentes prácticas en algunos aspectos de las previstas en el Código de Menores de 1927 y 1979. "Si, en el Código de Menores, el objeto era el más pequeño; en el Estatuto de la Niñez y la Adolescencia, el objeto es el niño y el adolescente como sujetos de derechos" (LEMOS, 2008, p.98). De esta manera, se inaugura una nueva identidad social llamada niños, niñas y adolescentes. No son solo las prácticas las que han cambiado, sino que el objeto es otro.

La ECA llega con una propuesta para construir un modelo de protección integral de niños, niñas y adolescentes, no solo restringiéndose a la atención después de que se violen los derechos, sino antes de que ocurra la violación, según lo previsto en su Art.70: "Es deber de todos prevenir la ocurrencia de una amenaza o violación de los derechos de los niños, niñas y adolescentes" (BRASIL, 1990). Esta ley federal garantiza, entre otros aspectos, la protección del niño contra cualquier tipo de violencia, incluida la violencia sexual.

Se sabe que, en la mayoría de los casos, el maltratador tiene una cercanía con la familia. Como muestran Santos, Costa y Granjeiro (2009), la mayoría de los casos de abuso sexual ocurren dentro de la familia, y en primer lugar practicados por los padres biológicos de las víctimas y, en segundo lugar, por los padrastros. Este es un

RC: 98976

Disponible: https://www.nucleodoconhecimento.com.br/psicologia-es/danos-aldesarrollo 
ejemplo de Violencia Intrafamiliar que, según Araújo (2002), es la violencia que ocurre en la familia, involucrando a personas que o no viven en el mismo lugar, pero que no se restringe solo a la familia, sino que involucra a sujetos de convivencia común en el mismo espacio doméstico, tengan o no lazos de parentesco. Para estos casos, el ECA tiene especificidades y una de ellas se menciona en el Art. 101:

$\S 2^{\circ}$ Sem prejuízo da tomada de medidas emergenciais para proteção de vítimas de violência ou abuso sexual e das providências a que alude 0 art. 130 desta Lei, o afastamento da criança ou adolescente do convívio familiar é de competência exclusiva da autoridade judiciária e importará na deflagração, a pedido do Ministério Público ou de quem tenha legítimo interesse, de procedimento judicial contencioso, no qual se garanta aos pais ou ao responsável legal o exercício do contraditório e da ampla defesa (BRASIL, 1990).

Estas leyes para proteger a los niños, niñas y adolescentes contra el abuso sexual son sumamente necesarias, ya que se trata de algo grave y puede causar muchos perjuicios a la víctima, como se señalará a continuación.

\subsection{DAÑOS A LA VÍCTIMA Y POSIBLES ACCIONES}

Entre las consecuencias que el abuso sexual puede causar a los niños y adolescentes, se pueden destacar: deficiencias cognitivas, conductuales, emocionales y sociales; aislamiento social, miedo exagerado, dificultades para adaptarse, ideas homicidas y suicidas, aprendizaje con déficit lingüístico, pérdida de interés en juegos y estudios, fugas de casa, automutilación, aislamiento social, agresividad y otras consecuencias que pueden comprometer gravemente la vida de la víctima (SERAFIM et al., 2011).

Prado y Carneiro (2005) discuten, desde la perspectiva del psicoanálisis, sobre el trauma que, según ellos, el término enfatizaría el daño generado en la capacidad de simbolizar y transformar, así como la corroboración de zonas psíquicas muertas, que interferirán en las generaciones futuras, alcanzando sus elecciones de amor y su perspectiva de lograr su sexualidad.Los autores discuten a partir de dos tipos de

RC: 98976

Disponible: https://www.nucleodoconhecimento.com.br/psicologia-es/danos-aldesarrollo 
traumas, proponiendo llamarlos activos y acumulativos, y el primero permanece en la psique de la persona repetidamente, especialmente cuando se trata de abuso sexual infantil, y puede tener las diversas manifestaciones, como promiscuidad, actuaciones, condiciones psicopáticas, depresiones, condiciones psicosomáticas, etc.

El trauma acumulativo se refiere a la tensión recurrente del incumplimiento del papel de la madre como escudo protector, que deja en la fase de desarrollo que el bebé necesita de la madre ejerciendo su rol; estas fallas maternas pueden ser susceptibles de corrección de acuerdo con el proceso de maduración. En cuanto al trauma activo, "de la misma manera que el trauma acumulativo, es traicionero, solo que en lugar de actuar y asentarse a lo largo de la infancia y la adolescencia, lo hace a lo largo de la vida, y más allá, ya que se reedue se reeduma a través de las generaciones" (PRADO; CARNEIRO, 2005, p.31). Por lo tanto, el trauma puede interferir y causar sufrimiento a lo largo de toda la vida de la víctima, trayendo varias posibilidades de efectos graves a largo plazo.

La relación del niño con adultos abusivos, resultando en la ruptura de la confianza y la inseguridad, favorece que la víctima no crea en la confiabilidad y seguridad de las personas en general, lo que puede reflejarse en sus relaciones futuras. Así, a partir de la adolescencia, se presentan casos de víctimas que, en su desesperación por obtener afecto, terminan convirtiéndose en promiscuas; por otro lado, otros rara vez se hacen disponibles para las relaciones; ambos casos avanzan hacia el aislamiento y la depresión (PRADO; CARNEIRO, 2005).

Padilha (2002) habla de la peculiaridad del abuso sexual, señalando que muchas veces no hay evidencia física de su consumación y luego el agresor argumenta que no obligó al niño a hacer nada. "Considerar esta característica del fenómeno parece ser fundamental en la planificación de intervenciones para la prevención o tratamiento de situaciones de abuso sexual, intrafamiliar o extrafamiliar" (PADILHA,

RC: 98976

Disponible: https://www.nucleodoconhecimento.com.br/psicologia-es/danos-aldesarrollo 
2002, p. 210). Por lo tanto, la prevención de dicha violencia requiere un conocimiento de los movimientos que impregnan las agresiones.

Como ya se mencionó, el Ministerio de Salud señala que el abuso sexual "se presenta en la forma de prácticas eróticas y sexuales impuestas a niños o adolescentes por violencia física, amenazas [...]" pero completas: "[...] o inducción de su voluntad" (BRASIL, 2002, p.13). Entonces, de hecho, la mayoría de los casos de abuso sexual ocurren bajo amenazas del agresor, a la sombra de la violencia, el chantaje, etc., sin embargo, inducir la voluntad de la víctima también constituye una agresión.

Todavía existe un concepto erróneo que considera que si el niño y especialmente el adolescente están conspirando con el acto sexual, la situación no constituiría como un abuso. Sin embargo, la ley brasileña no deja lugar a dudas de que los niños y adolescentes son vulnerables ya que, como ya se ha traído a esta investigación, si la persona se encuentra en una etapa de desarrollo psicosexual antes que la víctima, será abuso sexual (BRASIL, 2002).

Por lo tanto, incluso si el niño o adolescente consiente el acto sexual, esto es claramente reprobable por la legislación brasileña. Al abordar los delitos sexuales contra los vulnerables, el artículo 217-A del Código Penal deja en claro que "Tener conjunción carnal o practicar otro acto libidinoso menor de 14 (catorce) años: Pen prisión, de 8 (ocho) a 15 (quince) años" (HARMS, 2016, p.577).

Además, el 6 de noviembre de 2017 el Tribunal Superior de Justicia (STJ) lanzó el sumario 593, que determina enfáticamente que es irrelevante para la tipificación del delito el consentimiento o no de la víctima:

O crime de estupro de vulnerável se configura com a conjunção carnal ou prática de ato libidinoso com menor de 14 anos, sendo irrelevante eventual consentimento da vítima para a prática do ato, sua experiência sexual anterior ou existência de relacionamento

RC: 98976

Disponible: https://www.nucleodoconhecimento.com.br/psicologia-es/danos-aldesarrollo 
amoroso com o agente. (Súmula 593, TERCEIRA SEÇÃO, julgado em 25/10/2017, DJe 06/11/2017) (BRASIL, 2017).

Así, la legislación brasileña deja aún más claro que independientemente de las circunstancias de aceptación o no del niño o adolescente, los factores mencionados sobre el abuso sexual se aplican y se constituyen como delitos.

Además, el hecho de que la víctima consienta de alguna manera puede provocar un aumento del sentimiento de culpa y agravar el daño emocional, además de corroborar su silencio sobre la violencia vivida y, en muchos casos, favorecer que el niño o adolescente siga siendo abusado sexualmente. Para Padilha (2002), la duración del abuso puede consistir en un episodio aislado o rutinario que dura varios años sin divulgación a terceros. La agresión se puede hacer con víctimas de cualquier edad, desde bebés o niños muy pequeños, hasta la adolescencia.

Además, las hipótesis sobre el comportamiento de colusión con dicha violencia se establecen de acuerdo con el comportamiento de la madre, padre o padrastro, o hijo, proveniente de la historia de vida, que a veces repite patrones de generaciones pasadas. La falta de un repertorio de autoprotección puede deberse a modelos inadecuados de padres, que pueden no haber tenido un modelo adecuado de sus padres, etc. "Este mecanismo de repetición intergeneracional de conductas de exposición al riesgo explicaría por qué las madres, padres o padrastros se vuelven "ciegos" en relación con el abuso sexual [...]" (PADILHA, 2002, p.211). Es decir, no pueden identificar la evidencia de violencia.

Además, la etapa de desarrollo en la que se encuentra la víctima tiene interferencia tanto en el proceso de descubrimiento como en el juicio del sospechoso: "El abuso infantil es un delito que a menudo solo puede probarse mediante el testimonio de niños en edad preescolar. Si el testimonio de un niño es incorrecto, un adulto inocente puede ser castigado injustamente" (PAPALIA; OLDS; FELDMAN, 2006, p. 301). Como señalan acertadamente los autores, el niño pequeño puede terminar "recordando" eventos que no han ocurrido; tienden a ser sugerentes y su discurso

RC: 98976

Disponible: https://www.nucleodoconhecimento.com.br/psicologia-es/danos-aldesarrollo 
puede ser inducido por otra persona, y es difícil discriminar la falsedad del discurso de un niño que es entrevistado por alguien que hace preguntas con detalles sesgados. Esto puede ocurrir principalmente con niños menores de cuatro años, porque en esta etapa los niños son más propensos a cometer errores al recordar detalles de un evento que varía con la repetición. Sin embargo, Habigzang, Ramos y Ekoller (2011) se refieren al momento de la revelación del abuso sexual como crucial en la vida de la víctima, ya que puede causar revictimización si los adultos no creen en el habla del niño, y no toman las medidas de protección adecuadas, que deben tener una red de apoyo afectivo y social, que esté compuesta por sistemas o personas significativas para la víctima.

\begin{abstract}
Nos casos de abuso sexual contra crianças e adolescentes compreende-se como constituinte da rede: família, escola, comunidade, Conselho Tutelar, Delegacia, Conselho de Direitos da Criança, Ministério Público e Juizado da Infância e Adolescência, abrigos, serviços de saúde (postos de saúde e hospitais) e assistência social (Centro de Referência da Assistência Social e Centro de Referência Especializado da Assistência Social) (HABIGZANG; RAMOS; KOLLER, 2011, p. 468).
\end{abstract}

Así, todas estas instituciones tienen la responsabilidad de proteger a la víctima, esforzándose por planificar y realizar intervenciones que minimicen efectivamente los efectos de la violencia que sufren los niños, niñas y adolescentes (HABIGZANG; RAMOS; KOLLER, 2011). La escuela destaca porque es un entorno presente en fases muy importantes de la vida de niños, niñas y adolescentes en su desarrollo.

Aún aclarando sobre la implicación en el desarrollo de la víctima de abuso sexual, Papalia; Olds y Feldman (2006) muestran las citas más comunes según la edad: en preescolar, destacan la ansiedad, las pesadillas y el comportamiento sexual inapropiado; en los niños en edad escolar, se observan comportamientos agresivos, problemas escolares, miedo, hiperactividad e incluso enfermedades mentales; finalmente, los adolescentes comúnmente presentan depresión, quejas físicas, huida, acciones ilegales, comportamientos autodestructivos o suicidas y abuso de sustancias.

RC: 98976

Disponible: https://www.nucleodoconhecimento.com.br/psicologia-es/danos-aldesarrollo 
Santos; Costa y Granjeiro (2009) señalan que la mayoría de los casos de abuso sexual ocurren dentro de la familia, y los casos más comunes de abuso sexual son practicados por los padres biológicos de las víctimas y, en segundo lugar, por los padrastros. Es un tipo de Violencia Intrafamiliar que, según Araújo (2002), ocurre en la familia involucrando a personas que residen o no en el mismo lugar, pero que no se restringe solo a la familia, sino que involucra a sujetos de convivencia común en el mismo espacio doméstico, tengan o no lazos de parentesco. Por lo tanto, se puede afirmar que existe el riesgo de que las personas idealicen un cierto estereotipo para tales abusadores, no pagando por ver que, incluso si son trabajadores, "padres de familia", contribuyentes, tienen una buena vida social, son personas ricas, amables y educadas o que aparentemente educan y cuidan bien a sus hijos, esto no significa que tales personas no puedan cometer abuso sexual, incluso si tienen una conducta encomiable hacia la sociedad.

"La mayoría de los pedófilos no tienen antecedentes penales y las personas en sus vidas los describen como trabajadores, religiosos y celosos cuidadores de su familia" (COHEN; MANNARINO, 2000a; apud HABIGZANG et al., 2005, pág. 346).

Además, los agresores con estereotipos vistos socialmente como buenos ciudadanos pueden provocar el acomodo de las personas a no cuidar la prevención con niños, niñas y adolescentes respecto al abuso sexual, ya que también puede confundir en el proceso de sospecha e identificación de esta violencia. Además, dependiendo de la relación que el agresor tenga con la familia, muchos de los casos no se denuncian. Por ejemplo, una madre puede no denunciar a su cónyuge porque confía en él, no dar crédito a la denuncia del niño o adolescente porque no quiere alejarse del cónyuge o porque depende del agresor para mantener a la familia, entre otras situaciones. Williams (2002) cita otro aspecto importante, que es el hecho de que la violencia sexual todavía se considera tabú, y a menudo la víctima misma es estigmatizada y a menudo tiene un sentimiento de culpa o vergüenza; esta, entre otras, es una de las razones de la no denuncia por parte de personas que forman o no parte de la familia de la víctima.

RC: 98976

Disponible: https://www.nucleodoconhecimento.com.br/psicologia-es/danos-aldesarrollo 
Sin embargo, Habigzang et al. (2005) presentan el mapeo de factores de riesgo para abuso sexual intrafamilar que fueron identificados en los procesos legales del Ministerio Público de Rio Grande do Sul - Brasil, analizando 71 expedientes que presentan el perfil de los agresores; una de las características llamativas era que la mayoría de los agresores estaban desempleados o con trabajo eventual. "EI desempleo es un factor de riesgo para la violencia intrafamiliar, ya que puede generar estrés y conflicto entre los miembros de la familia" (HABIGZANG et al., 2005, p. 345). Además, el cuidador termina siendo responsable del niño o adolescente la mayor parte del tiempo, lo que brinda más oportunidades para la ocurrencia de abuso sexual. Otras características encontradas en la mayoría de los abusadores de este estudio son: bajo nivel de educación, casados o que viven maritalmente, consumidores de alcohol o drogas, entre otras cosas. Es importante destacar que estas características se encontraron en un porcentaje de los casos estudiados y, aunque son bastante comunes, son muchos los maltratadores que no presentan ninguna de estas características. Por lo tanto, es importante que los adultos estén atentos y busquen información que aumente sus conocimientos sobre el tema y así poder crear una red de protección para niños, niñas y adolescentes, pudiendo no solo identificar, sino prevenir, prevenir que ocurran abusos sexuales.

Para Brino y Williams (2005), el abuso sexual infantil se puede prevenir a través de acciones que se pueden dividir en tres niveles de prevención. El primer nivel es el nivel primario, que tiene como objetivo eliminar o reducir los factores sociales, ambientales y culturales que conducen a los actos de agresión. Así, se pueden impulsar acciones dirigidas a la formación de profesionales y otras personas directamente implicadas con el niño, como los profesores. Además, se pueden promover acciones con la población en riesgo, promoviendo la educación de los niños sobre los riesgos del abuso sexual.

Santos e Ippolito (2009) sostienen que la educación sexual es la mejor manera de prevenir, y que a pesar de pertenecer al adulto responsable de la educación de niños y adolescentes, la responsabilidad de protegerlos contra el abuso sexual, un

RC: 98976

Disponible: https://www.nucleodoconhecimento.com.br/psicologia-es/danos-aldesarrollo 
programa de educación continua es capaz de preparar a los niños y adolescentes para defenderse de esta violencia.

Otro medio de prevención mencionado por los autores es la inclusión social del niño considerado como "diferente", o rechazado por los grupos. "Después de la subyugación del niño al abuso sexual sufrido en el hogar o en el vecindario o su silencio ante él, generalmente hay una búsqueda de aceptación y afecto de un ser querido" (SANTOS; IPPOLITO, 2009, p.128). Por lo tanto, muchos de los niños que fueron víctimas de abuso sexual tenían un bajo nivel de autoestima y, en general, crecieron aislados en sus propios hogares y en la comunidad en la que viven, viéndose a sí mismos como diferentes de los demás y sin tener orientaciones sexuales fundamentales.

Con el objetivo de la prevención, Santos e Ippolito (2009) sugieren a las escuelas que promuevan la sensibilización de los miembros de la familia responsables de la educación de los niños y adolescentes, utilizando la creatividad de sus educadores para trabajar con estas familias, alentándolas y enseñándoles a fortalecer a los niños y adolescentes contra el abuso sexual; mantener una relación de confianza con el niño; dedicarle tiempo, y escuchar abiertamente lo que el niño tiene que decir, no trivializando en los casos en que el niño abusado "rompe el silencio", pensando que debe estar inventando los hechos y; construir una red de apoyo social entre los miembros de la familia en el trabajo para proteger al niño en los momentos en que el miembro de la familia que es responsable de la educación del más joven tiene que abandonar el hogar. Los autores afirman que: "La mayoría de los actos de abuso intra y extrafamiliar ocurren cuando el niño está solo con jóvenes y adultos en su propia casa o en la casa de conocidos" (SANTOS; IPPOLITO, 2009, p.129).

El segundo enfoque, según Brino y Willians (2005), es el secundario, que tiene como objetivo detectar precozmente a los niños en riesgo, evitando así la repetición de actos de violencia, trabajando para reducir el estrés causado por el proceso en el sistema legal que atraviesa el niño, considerando que la postura de los profesionales

RC: 98976

Disponible: https://www.nucleodoconhecimento.com.br/psicologia-es/danos-aldesarrollo 
que trabajan con el niño puede suavizarse o terminar produciendo daño psicológico a la víctima. El tercer y último enfoque presentado por los autores es el terciario; tiene como objetivo monitorear a la víctima, así como al agresor, por profesionales capacitados, con el fin de prevenir o mitigar las pérdidas causadas por el abuso sexual, así como las posibles secuelas a largo plazo.

Considerando la importancia de trabajar con la prevención del abuso sexual, actuando junto con los responsables $\mathrm{y} / \mathrm{o}$ con el niño, es posible planificar intervenciones dirigidas a la prevención primaria y secundaria. Las madres, por ejemplo, pueden desempeñar un papel decisivo en la protección contra esta violencia. "Cuando no pueden reconocer la ocurrencia de abuso sexual y protección, el niño puede volverse más vulnerable al abuso" (BRINO; WILLIANS, 2005, p.176). De ahí la importancia de buscar formas de informar a las madres sobre el abuso sexual para que puedan proteger al niño de la ocurrencia de este tipo de agresiones, y la escuela puede ser un lugar estratégico para dicha acción, ya que es una institución capaz de promover intervenciones aprovechando el contacto directo con los padres, niños y adolescentes.

Brino y Williams (2005) refuerzan la idea de que empoderar a los niños y las madres para que reconozcan las señales de que el abuso sexual está ocurriendo puede ser una acción que detenga efectivamente la ocurrencia de dicha violencia. Esta intervención dirigida al niño incluiría el reconocimiento de signos de acercamiento a un agresor, así como el reconocimiento de conductas sexuales inapropiadas. Para las madres, la acción implicaría reconocer comportamientos que son indicadores de abuso exitoso. Cuando la propuesta de la acción es la detección de niños, niñas y adolescentes en riesgo, rompiendo con actos violentos o sus repeticiones, interviniendo en casos ya confirmados y trabajando en la prevención de posibles secuelas, esta perspectiva se ajusta a la prevención secundaria o incluso terciaria.

Además de la prevención, es de fundamental importancia que sepamos qué hacer si ya se ha producido el abuso sexual. Es necesario saber denunciar, cuidar a la

RC: 98976

Disponible: https://www.nucleodoconhecimento.com.br/psicologia-es/danos-aldesarrollo 
víctima dando el apoyo necesario y derivando a tratamientos especializados (BRINO; WILLIAMS, 2003b, p.2).

Una de las formas de denunciar, como se muestra en el sitio web de UNICEF[7], es poniéndose en contacto con el Consejo de Tutela, considerando que es responsabilidad de los consejeros garantizar los derechos de los niños, niñas y adolescentes. Al recibir la notificación, depende de estos profesionales analizar el origen de cada caso, realizando visitas a la familia. Si así se confirma, el Consejo remitirá la situación al Ministerio Público.

Otro medio de denuncia señalado por UNICEF es ponerse en contacto con los Juzgados de Menores y Juvenil, en el caso de municipios que no cuentan con el Consejo de Tutela. También se pueden presentar denuncias en las comisarías de protección de la infancia y la adolescencia y en las comisarías de la mujer. También hay una aplicación para teléfonos inteligentes y tabletas llamada Proteja Brasil, que muestra los teléfonos y la ubicación de la institución especializada más cercana a la del denunciante. Además la aplicación ofrece asistencia en caso de dudas sobre el tipo de violencia.

Dial 100 - Derechos Humanos es un canal en el que "las denuncias pueden ser anónimas o, cuando lo solicite el denunciante, se garantiza la confidencialidad de la fuente de información" (BRASIL, s/d). De esa manera cualquiera puede denunciarlo sin ser identificado. Denunciar no es sinónimo de acusar, ya que es el profesional especializado quien investigará los hechos. Por lo tanto, es importante enfatizar que no es necesario estar seguro de que se ha producido un abuso sexual para que se realice la denuncia. Es un acto de compromiso con la seguridad y el bienestar del niño y adolescente, y la omisión es un acto tan grave como el propio abuso sexual. El ECA, en un único párrafo del artículo 70-B, determina que

São igualmente responsáveis pela comunicação de que trata este artigo, as pessoas encarregadas, por razão de cargo, função, ofício, ministério, profissão ou ocupação, do cuidado, assistência ou guarda

RC: 98976

Disponible: https://www.nucleodoconhecimento.com.br/psicologia-es/danos-aldesarrollo 
de crianças e adolescentes, punível, na forma deste Estatuto, o injustificado retardamento ou omissão, culposos ou dolosos (BRASIL, 1990).

El Estatuto, entonces, enfatiza la responsabilidad de las personas, que de alguna manera están involucradas en la vida del niño y adolescente, de presentar la denuncia en caso de violación de sus derechos. Esto reafirma la obligación de denunciar un acto tan grave como el abuso sexual, aunque sea una sospecha.

A la vista de estas notas, se entiende que el abuso sexual es un tema grave, con una amplia historia, que impregna las discusiones políticas, los valores culturales (que cambian según las regiones del mundo, y con el momento histórico), y por cuestiones de salud física, psicológica y social, que pueden comprometer seriamente la vida de muchos niños, niñas y adolescentes.

\section{CONSIDERACIONES FINALES}

Este artículo tuvo como objetivo abordar los aspectos históricos del abuso sexual, revisando la legislación brasileña y explorando las complejidades del tema incluso en relación con la definición y la nomenclatura.

Se vio que los niños, niñas y adolescentes no siempre fueron considerados como seres humanos que necesitan un respeto y cuidado específico y que, a lo largo de la historia, se cometieron diversos tipos de violencia contra este público sin castigo a los agresores, ni siquiera la atención de los poderes públicos para proteger a estas personas.

Ante varios casos de crueldad y negligencia, se están instituyendo leyes a favor de los niños y adolescentes y, en Brasil, la ECA marca el establecimiento de varios derechos, previendo la protección de los menores y exigiendo que los adultos sean responsables de cuidarlos.

RC: 98976

Disponible: https://www.nucleodoconhecimento.com.br/psicologia-es/danos-aldesarrollo 
Así, el abuso sexual es uno de los fenómenos que ha llamado la atención del Estado $y$, actualmente, se han establecido medidas de protección contra dicha violencia. Los estudios muestran los daños biopsicosociales que esta agresión puede causar a la víctima y a su familia, así como los mecanismos que implican la práctica del abuso sexual, permitiendo tomar estrategias de prevención y que se identifiquen y castiguen agresores de diferentes perfiles.

Sin embargo, se sabe que la población en general aún carece de conocimientos sobre el tema, incluidos los miembros de la familia y las instituciones que se encargan de la protección de los niños, niñas y adolescentes como la escuela, por ejemplo. Además, la falta de aclaración sobre este fenómeno es un factor que corrobora que esta violencia se siga reproduciendo. Existe, entonces, la necesidad de más investigaciones e intervenciones que brinden a la población cada vez más información sobre el tema, concientizando sobre el compromiso de todos a favor de garantizar los derechos de los niños, niñas y adolescentes, potenciando así la lucha contra el abuso sexual.

\section{REFERENCIAS}

ADED et al. Abuso sexual em crianças e adolescentes: revisão de 100 anos de literatura. Revista de Psiquiatria Clínica 33 (4); 204-213, 2006. [online]. Disponível em: <http://www.hcnet.usp.br/ipq/revista/vol33/n4/204.html>. Acesso em: 27 de mai. de 2015.

ARAÚJO, M. de F. Violência e Abuso Sexual na Família. Psicologia em Estudo, Maringá, v. 7, n. 2, p. 3-11, jul./dez. 2002. [online]. Disponível em: <http://www.scielo.br/scielo.php?pid=S1413-

$73722002000200002 \&$ script=sci_arttext>. Acesso em: 09 de set. de 2015.

AZAMBUJA, M. R. F. de. Violência sexual intrafamiliar: é possível proteger a criança? Revista Virtual Textos \& Contextos, oㅡ 5, nov. 2006. [online]. Disponível em:

RC: 98976

Disponible: https://www.nucleodoconhecimento.com.br/psicologia-es/danos-aldesarrollo 
<http://revistaseletronicas.pucrs.br/ojs/index.php/fass/article/view/1022>. Acesso em 09 de set. de 2015.

BRASIL. Ministério da Saúde. Notificação de maus-tratos contra crianças e adolescentes pelos profissionais de saúde. Secretaria de Assistência à Saúde. Série A. Normas e Manuais Técnicos; n. 167. Brasília-DF, 2002. [online]. Disponível em: <http://bvsms.saude.gov.br/bvs/publicacoes/notificacao_maustratos_criancas_adoles centes.pdf>. Acesso em: 27 de mai. de 2015.

Site: Conselho Nacional de Saúde. 18 de maio - Dia nacional de combate ao abuso e exploração sexual de crianças e adolescentes. s/d. Disponível em <http://conselho.saude.gov.br/ultimas_noticias/2009/15_mai_caesca.htm>. Acesso em: 06 de jun. de 2016.

_. Constituição (1988). Constituição da República Federativa do Brasil: promulgada em 5 de outubro de 1988. [online]. Disponível em: <http://www.planalto.gov.br/ccivil_03/Constituicao/Constituicao.htm>. Acesso em: 07 de out. de 2016.

. Estatuto da Criança e Adolescente. Lei 8.069, de 13 de julho de 1990. Brasília, 1990. [online]. Disponível

em: <http://www.planalto.gov.br/ccivil_03/LEIS/L8069.htm>. Acesso em 09 de set. de 2015

Superior Tribunal de Justiça. Súmula 593. O crime de estupro de vulnerável se configura com a conjunção carnal ou prática de ato libidinoso com menor de 14 anos, sendo irrelevante eventual consentimento da vítima para a prática do ato, sua experiência sexual anterior ou existência de relacionamento amoroso com o agente. Terceira Seção. Julgado em 25/10/2017. DJe 06/11/2017. Disponível em <https://www.stj.jus.br/sites/portalp/Inicio>. Acesso em: 14 de abr. de 2021.

$\mathrm{RC}: 98976$

Disponible: https://www.nucleodoconhecimento.com.br/psicologia-es/danos-aldesarrollo 
BRINO, R. F.; WILLIAMS, L. C. Capacitação do educador acerca do abuso sexual infantile. Interação em Psicologia, 7(02), p. 1-10, 2003b. [online]. Disponível em:<file:///C:/Users/Usuario/Downloads/3218-6348-1-PB\%20(1).pdf>. Acesso em 13 de abr. de 2016.

. Prevenção primária, secundária e terciária do abuso sexual infantil. In:Sobre o comportamento e cognição- Expondo a variabilidade. Org. GUILHARDI, H. J.; AGUIRRE, N. C. de. p.174-181, 2005.

DECLARAÇÃO UNIVERSAL DOS DIREITOS HUMANOS, Adotada e proclamada pela resolução 217 A (III) da Assembléia Geral das Nações Unidas em 10 de dezembro de 1948. Representação da UNESCO no Brasil. Brasília, 1998. [online] Disponível em: <http://unesdoc.unesco.org/images/0013/001394/139423por.pdf>. Acesso em: 05 de jun. de 2016.

FALEIROS, E. T. S; CAMPOS, J. de O. C. Repensando os conceitos de violência, abuso e exploração sexual de crianças e de adolescentes. CECRIA / MJ-SEDH-DCA / FBB / UNICEF. Brasília, 2000. [online] Disponível em: $<$ http://escca.luizaugustopassos.com.br/wpcontent/uploads/2011/02/livro_repensando_os_conceitos_eva_publicacoeshttpwww.mpes_.gov_.branexoscentros_apoioarquivos1.pdf1.pdf>. Acesso em: 02 de jun. de 2016.

GUERRA, A. M. A. et al. Crianças e adolescentes têm direitos: conheça o Sistema de Garantia dos Direitos e saiba como participar. Org. GRACIANI, M. S. S. et al. $1^{\text {a }}$ ed. São Paulo: CONDECA: Manufatura de ideias, 2013.

HABIGZANG, L. F. et al. Abuso sexual infantil e dinâmica familiar: aspectos observados em processos jurídicos. Psicologia: Teoria e Pesquisa, Brasília, v. 21,
n.3,
p.341-348,
2005.
Disponível

RC: 98976

Disponible: https://www.nucleodoconhecimento.com.br/psicologia-es/danos-aldesarrollo 
em:<http://www.scielo.br/scielo.php?script=sci_arttext\&pid=S0102$37722005000300011 \&$ Ing=en\&nrm=iso $>$. Acesso em: 07 de set. de 2016.

HABIGZANG, L. F.; RAMOS, M. da S.; KOLLER, S. H. A Revelação de Abuso Sexual: As Medidas Adotadas pela Rede de Apoio. Psicologia: Teoria e Pesquisa Out-Dez 2011, Vol. 27 n. 4, pp. 467-473. [online]. Disponível em: <http://www.scielo.br/pdf/ptp/v27n4/10.pdf>. Acesso em: 09 de set. de 2015.

HARMS, M. (org.) Vade Mecum RT. [Equipe RT]. 12 ed. revista, atualizada e ampliada. São Paulo: Editora Revista dos Tribunais, 2016. ISBN 978-85-203-6714-8.

INOUE, S. R. V.; RISTUM, M. Violência sexual: caracterização e análise de casos revelados na escola. Estudos de Psicologia (Campinas) [online]. 2008, vol.25, n.1, pp. 11-21. ISSN 1982-0275. Disponível em: $<$ http://www.scielo.br/scielo.php?pid=S0103166X2008000100002\&script=sci_abstract\&tIng=pt>. Acesso em: 27 de mai. de 2015.

LEMOS, F. C. S. O Estatuto da Criança e do Adolescente no Brasil atual. Revista Psicologia Política, São Paulo, v. 8, n. 15, p. 93-106, jun. 2008. Disponível em $<$ http://pepsic.bvsalud.org/scielo.php?script=sci_arttext\&pid=S1519549X2008000100007\&lng=pt\&nrm=iso $>$. Acesso em:08 de jun. de 2016.

MINAYO, M. C. S. O significado social e para a saúde da violência contra crianças e adolescentes. In:WESTPHAL, M. F. (org). Violência e criança. São Paulo: Edusp, 2002.

OLIVEIRA, I. S. de. Trajetória Histórica do Abuso Sexual Contra Criança e Adolescente. UniCEUB: Brasília. 2006. Professor-orientador: Dr. Maurício Neubern.

PADILHA, M. da G. S. Abuso sexual contra crianças e adolescentes: considerações sobre os fatores antecedentes e sua importância na prevenção. In: GUILHARDI, H.

RC: 98976

Disponible: https://www.nucleodoconhecimento.com.br/psicologia-es/danos-aldesarrollo 
J.; AGUIRRE, N. C. (Orgs.) Sobre Comportamento e Cognição: Expondo a variabilidade. Santo André: ESETec, 2002, v.10, p. 209 a 220.

PAPALIA, D.; OLDS, S.W.; FELDMAN, R. D. Desenvolvimento Humano. 8 ed.Porto Alegre: Artmed, 2006.

PRADO, M. do C. de A.; CARNEIRO, T. F. Abuso sexual e traumatismo psíquico. Interações, São Paulo, v. 10, n. 20, p. 11-34, dez. 2005. [online] Disponível em:<http://pepsic.bvsalud.org/scielo.php?script=sci_arttext\&pid=S1413$29072005000200002 \&$ Ing=pt\&nrm=iso>. Acesso em: 23 de abr. de 2016.

SANTOS. B. R. dos; IPPOLITO, R - Childhood Brasil. O papel da escola no enfrentamento da violência sexual. In: LAVARELLO, F. (Coord). A defesa de crianças e adolescentes vítimas de violências sexuais. São Paulo: Cromosete, 2009, p. $125-130$.

SANTOS, V. A. dos; COSTA, L. F.; GRANJEIRO, I. A. C. L. Intervenção no abuso sexual intrafamiliar: ingerência invasiva ou proteção devida? Psico, Porto Alegre, PUCRS, v. 40, n. 4, pp. 516-524, out./dez. 2009. [online]. Disponível em: <http://revistaseletronicas.pucrs.br/ojs/index.php/revistapsico/article/view/4009>. Acesso em: 09 de set. de 2015.

SERAFIM, A. de P. et al. Dados demográficos, psicológicos e comportamentais de crianças e adolescentes vítimas de abuso sexual. Revista de Psiquiatria Clínica, São Paulo, v. 38, n. 4, p. 143-147, 2011. [online]. Disponível em: $<$ http://www.scielo.br/scielo.php?script=sci_arttext\&pid=S010160832011000400006>. Acesso em: 09 de set. de 2015.

UNICEF. Situação mundial da infância (edição especial): celebrando 20 anos da Convenção sobre os Direitos da Criança. UNICEF, 2009. [online] Disponível em: $<$ http://www.unicef.org/brazil/pt/sowc_20anosCDC.pdf>. Acesso em: 03 de jun. de 2016.

RC: 98976

Disponible: https://www.nucleodoconhecimento.com.br/psicologia-es/danos-aldesarrollo 
VEGA, L. B. da S.; PALUDO, S. dos S. Exploração sexual e rede de proteção na perspectiva da vítima. Arquivos Brasileiros de Psicologia, Rio de Janeiro, v. 67, n. 2, p. 47-60, 2015.

Disponível em <http://pepsic.bvsalud.org/scielo.php?script=sci_arttext\&pid=S1809$52672015000200005 \&$ Ing=pt\&nrm=iso >. Acesso em: 29 de maio de 2016.

WAISELFISZ, J. J. Atendimento por Violência No SUS. In: Mapa da Violência 2012: Crianças e Adolescentes do Brasil. 1 ed. Rio de Janeiro: CEBELA, 2012. p.62-73.

WILLIAMS, L. C. A. Abuso sexual infantil. In: GUILHARDI, H. J.; AGUIRRE, N. C. (Orgs.). Sobre Comportamento e Cognição: Expondo a variabilidade. Santo André: ESETec, 2002, v.10, p.155-164.

\section{APÉNDICE - NOTA DE REFERENCIA}

3. Datos obtenidos en https://agenciapatriciagalvao.org.br/violencia/violenciasexual/tres-criancas-ou-adolescentes-sao-abusadas-sexualmente-no-brasil-a-cadahora/

4. Sitio web de Portal Brasil: < http://www.brasil.gov.br/cidadania-ejustica/2015/07/em-1927-o-brasil-ganhou-oprimeiro-codigo-de-menores> .

5. Sitio web de DUDH: < http://www.dudh.org.br/declaracao/> .

6. Sitio web de CRAMI: <http://www.cramicampinas.org.br

7. Sitio web de UNICEF: <http: www.unicef.org/brazil/pt/activities_10790.htm="'">.</http:>

Enviado: Mayo de 2021.

Aprobado: Septiembre de 2021.

RC: 98976

Disponible: https://www.nucleodoconhecimento.com.br/psicologia-es/danos-aldesarrollo 